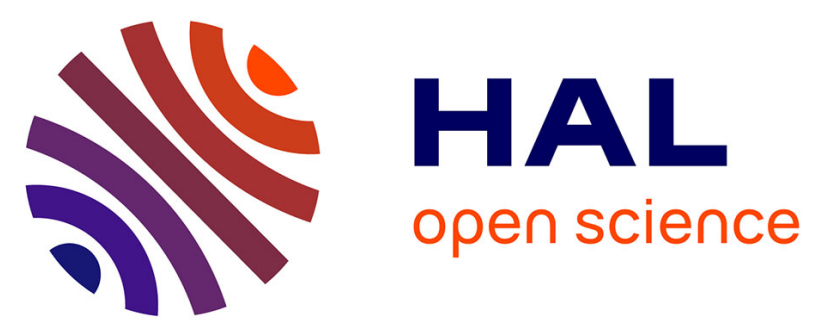

\title{
Axial Field Synchronous Machine with Homopolar Flux in the airgap for a Flywheel Accumulator
}

Nicolas Bernard, Hamid Ben Ahmed, Bernard Multon

\section{To cite this version:}

Nicolas Bernard, Hamid Ben Ahmed, Bernard Multon. Axial Field Synchronous Machine with Homopolar Flux in the airgap for a Flywheel Accumulator. IEEE Industry Application Society Annual Meeting 2002, Oct 2002, PITTSBURG, United States. 8p. hal-00674689

\section{HAL Id: hal-00674689 \\ https://hal.science/hal-00674689}

Submitted on 27 Feb 2012

HAL is a multi-disciplinary open access archive for the deposit and dissemination of scientific research documents, whether they are published or not. The documents may come from teaching and research institutions in France or abroad, or from public or private research centers.
L'archive ouverte pluridisciplinaire HAL, est destinée au dépôt et à la diffusion de documents scientifiques de niveau recherche, publiés ou non, émanant des établissements d'enseignement et de recherche français ou étrangers, des laboratoires publics ou privés. 


\title{
AXIAL-FIELD SYNCHRONOUS MACHINE WITH HOMOPOLAR FLUX IN THE AIRGAP FOR A FLYWHEEL ACCUMULATOR
}

\author{
Nicolas BERNARD \\ Hamid BEN AHMED \\ Laboratory of Electricity, Signals and Robotics (LESiR UPRESA CNRS 8029) \\ Ecole Normale Supérieure de Cachan - Brittany Branch \\ Ker Lann Campus - 35170 Bruz, France \\ Phone: 33 (0)2 99059331 - Fax: 33 (0)2 99059305 \\ e-mail: bernard@bretagne.ens-cachan.fr
}

Bernard MULTON

\begin{abstract}
A new axial-field synchronous machine designed for a flywheel accumulator is presented herein. The armature and field windings fixed in the airgap are made with double-face printed circuits. $A$ specific armature layout provides a sinedistributed m.m.f. and solves the problem of crossing the ends of the winding. A $2 D$ semi-analytical model at the mean radius, using surfacic permeances, is then developed. Afterwards, inductances, torque and eddy current losses are calculated using this model and compared with experimental results.
\end{abstract}

Keywords: flywheel accumulator, axial-field synchronous machine, double-face printed winding, surfacic permeance.

\section{INTRODUCTION}

Increasing reliance on renewable energy sources, coupled with the recent liberalization of the European electricity market, has generated some major changes. The development of many thousands of smaller generators (using wind power, photovoltaic power, etc.) appears to be improving both the safety of energy supplies and respect for the environment $[1,2]$. Electricity production therefore tends toward a distributed generation in which energy storage is a key element. Within such a context, flywheel systems, owing to their characteristics, could provide a worthwhile solution. They are capable of delivering high power, limited only by the motor/generator rating and power electronics, with the number of charge/discharge cycles remaining very high; moreover, these systems prove to be highly efficient.

\section{MACHINE DESIGN}

The machine presented herein (see Figs. 1 and 2) is an integrated synchronous motor/generator (see the geometric dimensions in the Appendix). It represents a new integrated topology [3] and has been specifically designed for flywheel energy storage. Both the magnetic bearings and vacuum envelope have not been discussed in this paper. The use of solid steel discs without any magnets and windings would appear mandatory due to the high speed required for this application. Furthermore, when a vacuum system is used, the behavior of brushes is poor even with DC current and heat transfer since the rotor is limited by conduction through the brushes.

The field coil fed by a DC current creates a homopolar flux in the airgap and magnetizes the solid steel discs. The rotation creates a rotative axial field. The torque is created by interaction between this field and the rotating field produced by the three-phase armature winding. In Fig. 2, the main parameters used in this paper are given.

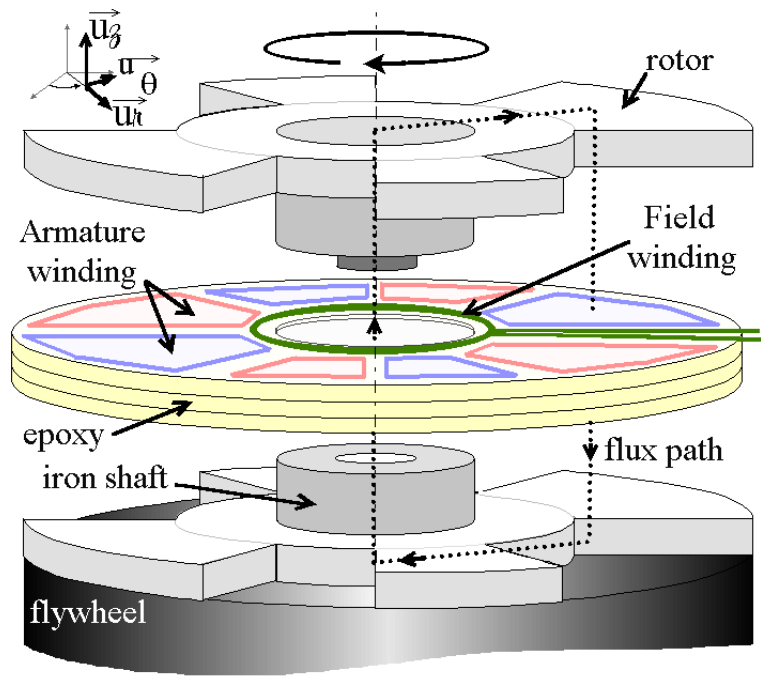

Fig. 1: Overview of the studied machine

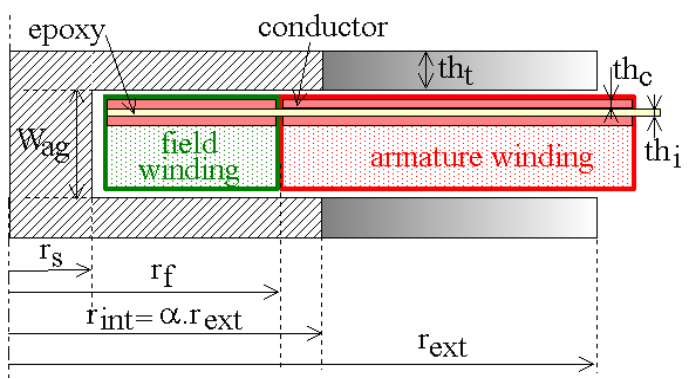

Fig. 2: Machine cross-section and main parameters

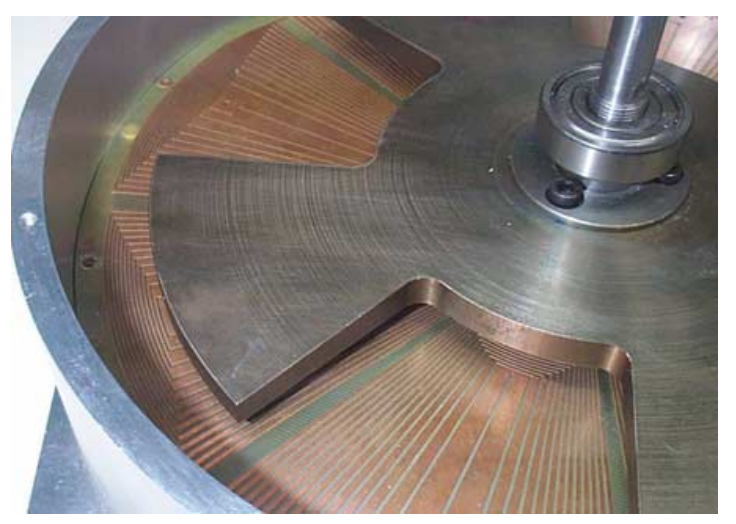

Fig. 3: Upper side of the machine (only the armature winding is visible) 


\section{WINDING}

The principle of the multilayer winding is displayed in Fig. 4. Only one two-layer elementary element is shown. This winding is a double-face printed circuit in which each pole is connected to the same pole on the other face. A phase is constituted by associating $\mathrm{n}_{\text {| }}$ electricallyconnected layers in series. For a three-phase motor with four pole pairs $(p=4)$, the phases are displaced by $120 / p$ mechanical degrees.

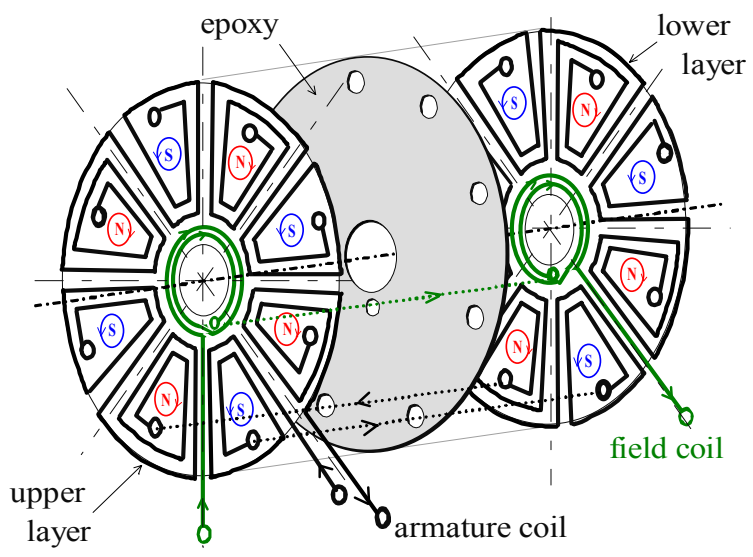

Fig. 4: Overview of the multilayer winding $\left(\mathrm{n}_{l}=2\right)$

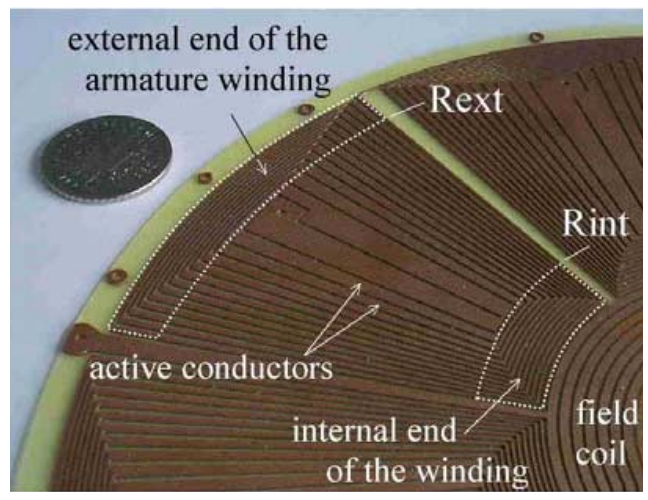

Fig. 5: View of a single layer

This technology is attractive because each phase is printed separately: the problem of crossing the ends of the windings has therefore been resolved. It is also possible to easily create any f.m.m. distribution through the use of short-pitched concentric windings and variable-width radial conductors. Moreover, a large width for the external ends of this kind of winding allows significantly reducing $\mathrm{I}^{2} \mathrm{R}$ losses. Nevertheless, a litz wire arrangement is not possible using such technology.

Fig. 6 shows the m.m.f. distribution in the case where only two radial conductors are represented. On the basis of the dotted line, which represents the desired m.m.f., the width of each conductor has been deduced; a sinedistributed m.m.f. has been chosen. The design of the winding is presented in Figs. 4 and 5, and the resultant m.m.f. distribution is depicted in Fig. 7. The number "n" of turns per elementary pole is equal to 13 . Elementary turns contain two radial conductors and are electrically connected in series.

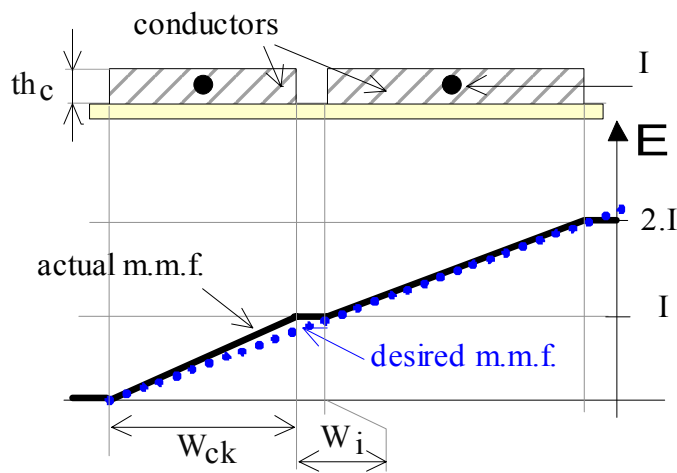

Fig. 6: m.m.f. distribution

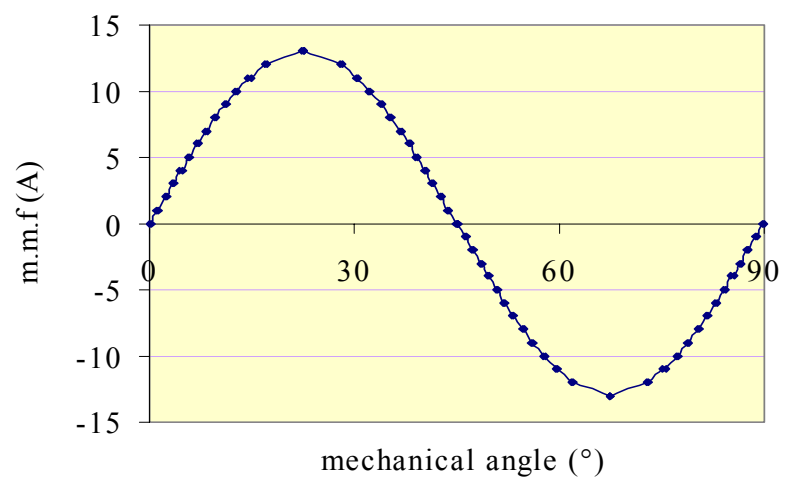

Fig. 7: m.m.f. distribution $(n=13, p=4)$

If the number of coils/pole/element is sufficient, the m.m.f. waveform is close to a perfect sine waveform, and the law that yields $\gamma_{\mathrm{k}}$, the mean arc of the $\mathrm{k}^{\text {th }}$ elementary coil, is:

$\gamma_{\mathrm{k}} \approx \frac{1}{\mathrm{p}} \mathrm{a} \cos \left(\frac{\mathrm{k}-1}{\mathrm{n}}\right)$

and:

$\mathrm{E}_{\mathrm{a}}(\theta) \approx \mathrm{n}_{\mathrm{l}} \cdot \mathrm{n} \cdot \mathrm{I}_{\mathrm{a}} \cos (\mathrm{p} \theta)=\mathrm{E}_{\mathrm{aM}} \cos (\mathrm{p} \theta)$

In the motor being described, the conductor thickness th and insulation width between two conductors $\mathrm{W}_{\mathrm{i}}$ are both constant and equal to $0.3 \mathrm{~mm}$ and $0.2 \mathrm{~mm}$, respectively. Measurements (outside of a vacuum envelope) have shown that the maximum current density is limited to $9 \mathrm{~A} / \mathrm{mm}^{2}$ in both armature and field windings.

\section{MAGNETIC FIELD IN THE AIRGAP}

Due to a large airgap, the flux density created by the field winding is far from having a rectangular distribution. An initial analysis, using both the 3D finite element method (F.E.M.) and measurements, illustrates this property. In Fig. 8a, it is shown that the flux density can be considered as independent of the axial position, except for positions close to the discs where proximity effects create some peaks. As will be shown in 
Section IX, such a phenomenon can significantly increase eddy current losses in the winding. In Fig. 8b, the flux density is plotted versus different radii (at $z=0 \mathrm{~mm}$ ). In this case, edge effects (3D effects) are illustrated. In Section $V$, it will be seen that for a ratio $(\alpha)$ between $r_{\text {ext }}$ and $r_{\text {int }}$ and close to 0.5 , a 2D model is sufficient.

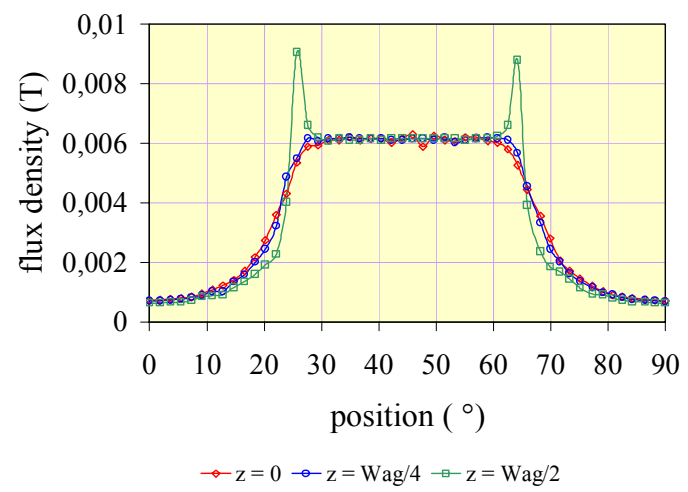

Fig. 8a: Flux density distribution for different positions in the airgap at the mean radius

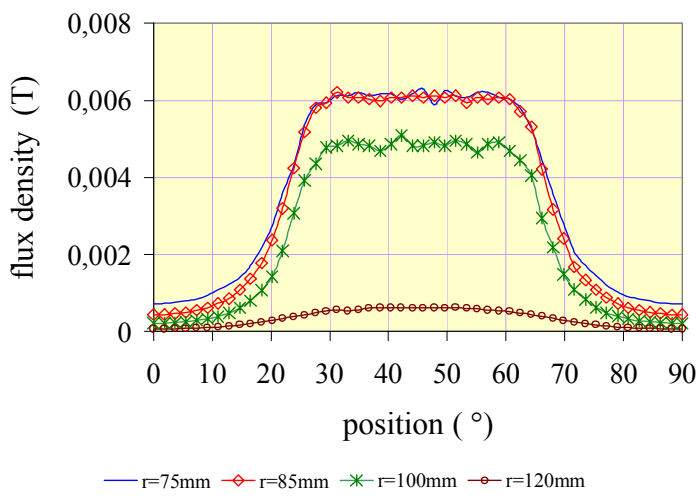

Fig. 8b: Flux density distribution for different radii in the center of the airgap $(z=0 \mathrm{~mm})$

Moreover, Fig. 8b shows that the flux density falls rapidly outside of the steel discs. Consequently, the flux linkage in the outer ends of the winding will be neglected in the following calculations. As regards the inner ends, flux density can be considered constant.

\section{2D SEMI-ANALYTICAL MODEL}

Due to the specific design, the flux density distribution in the airgap cannot be given by means of a simple rectangular function, as in the case of a small airgap [4]. A complete $2 \mathrm{D}$ analytical model is therefore no longer sufficient.

Calculation using a 2D semi-analytical model is proposed in this paper. It will be shown that knowledge of the flux distribution in the airgap, through a $2 \mathrm{D}$ finite element method (F.E.M.) and at the mean radius, is in fact sufficient. It then becomes necessary to define a 2D representation capable of describing the structure's behavior with sufficient accuracy. Considering the flux line path (Fig. 9) created by the field winding at the mean radius, a $2 \mathrm{D}$ equivalent basic pattern is deduced and represented in Fig. 10a.

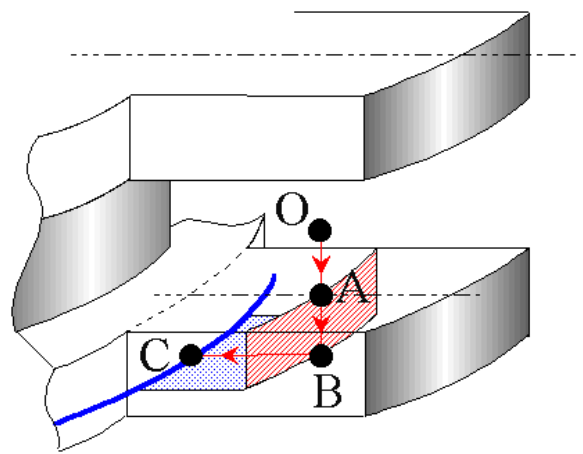

Fig. 9: Mean flux line path

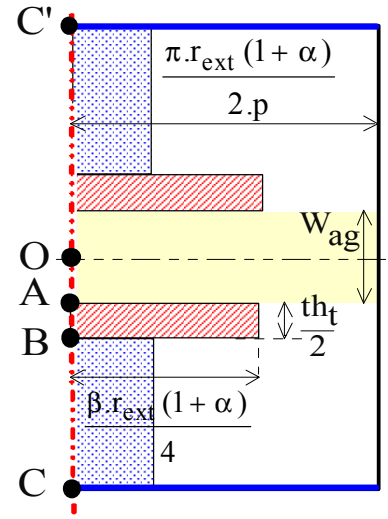

Fig. 10a: 2D basic pattern

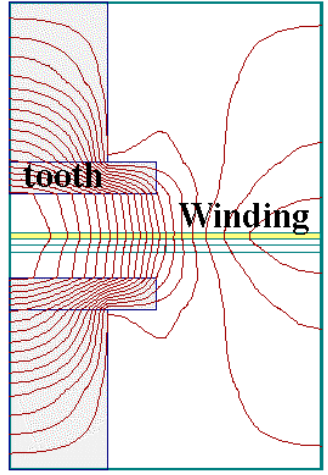

Fig. 10b: Flux plot (created by one phase)
The flux distribution created by the field winding is calculated by applying a m.m.f., denoted $E_{f}$, between $C$ and $C$ ' (see Fig. 10a). For the case of the flux distribution created by one phase, the m.m.f. in this phase is to be imposed (Fig. 10b).

For an armature winding such as the winding presented herein, the sine-distributed m.m.f. is difficult to compute. In addition, determining the armature flux density for each rotor position requires several computations. Hence, the computation time may become excessive, particularly for optimization calculations.

One solution, which consists of making use of surfacic permeances, is capable of significantly reducing this computation time. Flux density is sometimes expressed in the form of a product of a surfacic permeance $P_{s}$ and a m.m.f. $E$ [5]. For example, the flux density in coil 2 , created by coil 1 , can be written as follows:

$$
\mathrm{B}_{12}\left(\theta_{\mathrm{R}}\right)=\mathrm{P}_{\mathrm{s} 12}\left(\theta-\theta_{\mathrm{R}}\right) . \mathrm{E}_{1}
$$

where $P_{s 12}$ expresses the surfacic permeance that translates the flux distribution in coil 2 when coil 1 is being fed. Such a formulation proves effective, especially as the airgap increases, since surfacic permeance depends solely upon geometric parameters. In the case of simple saliency, only one calculation (for one position) using an F.E.M. computation is therefore 
necessary. Inductions for all positions are then deduced from a Fourier analysis of the permeance and computation time is significantly reduced. In addition, the surfacic permeance $P_{s 12}$ can be given since a rectangulardistributed m.m.f. is simplest and well-adapted to the numerical processing (see Fig. 11). In this analysis, the machine is assumed to operate under linear magnetic conditions.

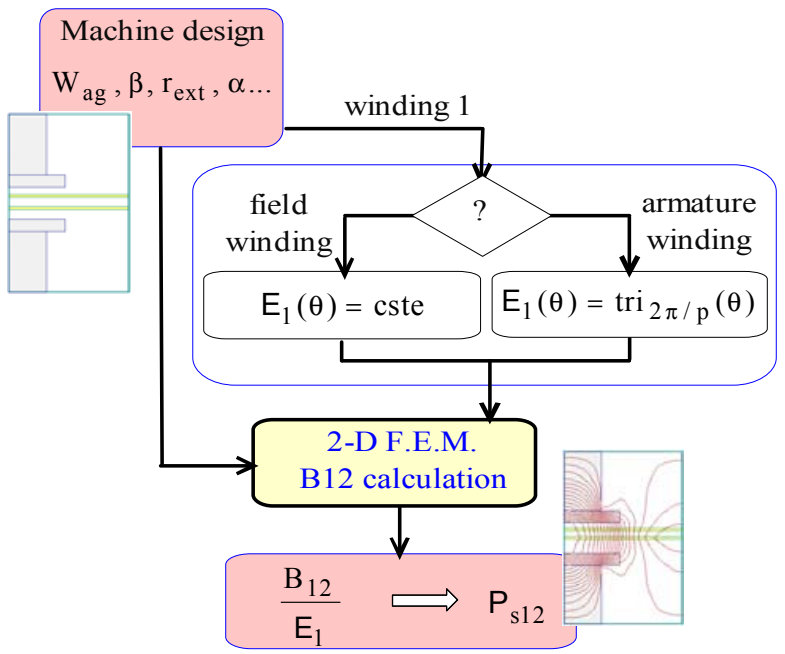

Fig. 11: 2D semi-analytical principle

Furthermore, it should be noted that the calculation takes into account parameters such as tooth width, winding thickness, winding position in the airgap and airgap thickness.

\section{E.M.F. CALCULATION}

The flux linkage of the winding is obtained by integrating the contribution of all elementary coils. By initially assuming the flux in the winding ends to be negligible, for a north pole containing $n$ turns, it is possible to express the flux linkage as follows (with the radial and angular positions being described by subscripts $r$ and $\theta$, respectively):

$\Phi_{\text {fa_N }}\left(\theta_{R}\right)=\sum_{k=1}^{n} \cdot \int_{R_{\text {int }}}^{R_{\text {ext }}} \cdot \int_{-\gamma_{k}}^{+\gamma_{k}} P_{\text {sfa }}\left(\theta-\theta_{R}\right) . E_{f 0} \cdot r \cdot d r . d \theta$

For a south pole, displaced by $\pi / \mathrm{p}$ :

$\Phi_{\mathrm{fa}_{-} \mathrm{S}}\left(\theta_{\mathrm{R}}\right)=-\Phi_{\mathrm{fa}_{-} \mathrm{N}}\left(\theta_{\mathrm{R}}+\frac{\pi}{\mathrm{p}}\right)$

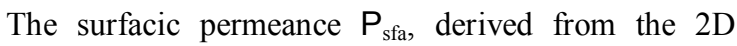
F.E.M. described in Section IV, can be written as:

$$
\mathrm{P}_{\text {sfa }}\left(\theta_{\mathrm{R}}\right)=\mathrm{P}_{\mathrm{sfa} 0}+\sum_{\mathrm{h}=1}^{+\infty} \mathrm{P}_{\text {sfah }} \cdot \cos \left[\mathrm{hp}\left(\theta-\theta_{\mathrm{R}}\right)\right]
$$

Furthermore:

$$
\mathrm{E}_{\mathrm{f} 0}=\mathrm{n}_{\mathrm{f}} \cdot \mathrm{I}_{\mathrm{f}}
$$

By introducing:

$$
A_{f a}=2 p \cdot n_{1} \cdot n_{f} \cdot I_{f} \cdot\left(r_{\text {ext }}^{2}-r_{\text {int }}^{2}\right)
$$

for a sine-distributed m.m.f., it is then possible to express the total flux linkage as follows:

$$
\Phi_{\mathrm{fa}}\left(\theta_{\mathrm{R}}\right)=\mathrm{A}_{\mathrm{fa}} \sum_{\mathrm{k}=1}^{\mathrm{n}} \cdot \sum_{\mathrm{h}=1}^{+\infty} \frac{\mathrm{P}_{\mathrm{sfah}}}{\mathrm{h}} \cdot \sin \left(\mathrm{hp} \gamma_{\mathrm{k}}\right) \cdot \cos \left(\mathrm{hp} \theta_{\mathrm{R}}\right)
$$

with $\mathrm{h}$ remaining uneven.

After division by $I_{f}$, mutual inductance is obtained and its distribution is plotted (see Fig. 12). Considering mutual inductance to be perfectly sinusoidal, then:

$$
\mathrm{M}_{\mathrm{fa}}\left(\theta_{\mathrm{R}}\right)=\mathrm{M}_{\mathrm{fa} M} \cdot \cos \left(\mathrm{p} \theta_{\mathrm{R}}\right)
$$

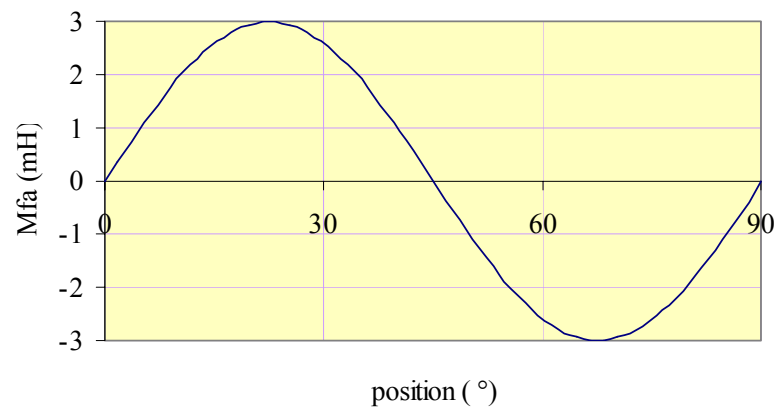

Fig. 12: Calculated mutual inductance $\mathrm{M}_{\mathrm{fa}}$ $\left(\right.$ airgap $\left.=10 \mathrm{~mm}, \beta=45^{\circ}\right)$

The e.m.f. equation based on mutual inductance is obtained from Faraday's law. The results have been plotted in Fig. 13.

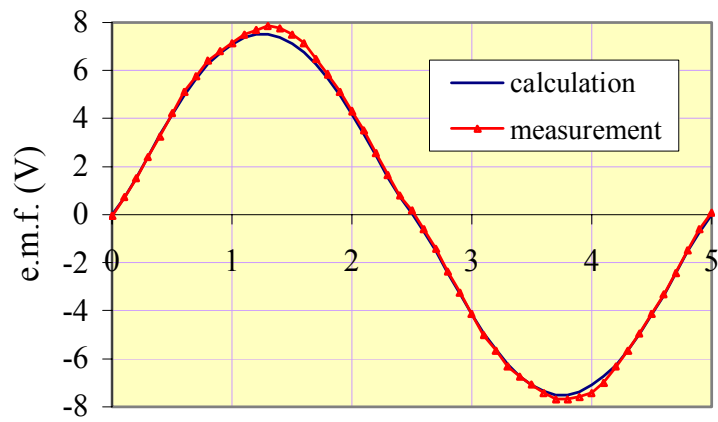

time (ms)

Fig. 13: Calculated and measured e.m.f.

$$
\left(\Omega=3000 \mathrm{rpm}, \mathrm{I}_{\mathrm{f}}=2 \mathrm{~A}, \text { airgap }=10 \mathrm{~mm}, \beta=45^{\circ}\right)
$$

For purposes of comparison, the maximum mutual inductance values obtained by calculation and measurement yield the following:

$$
\begin{array}{ll}
\mathrm{M}_{\mathrm{fa} \mathrm{M}}=3 \mathrm{mH} & \text { calculation } \\
\mathrm{M}_{\mathrm{fa} \mathrm{M}}=3.1 \mathrm{mH} & \text { measurement }
\end{array}
$$


The difference between measurement and calculation of the e.m.f. (Fig. 13) is less than 3\%, in spite of the approximations introduced. Different measurements, for different airgap lengths and different positions of the windings, have been performed. Concerning mutual inductance, the principle used has therefore proved to be satisfactory.

\section{INDUCTANCE CALCULATION}

\section{A. Armature self-inductance}

Inductances are obtained in a similar way. Consider, for example, the flux linkage of winding "a" due to its own current $I_{a}$, which is calculated as follows:

$\Phi_{\mathrm{aa}}\left(\theta_{\mathrm{R}}\right)=\sum_{\mathrm{k}} \cdot \int_{\mathrm{r}_{\mathrm{int}}}^{\mathrm{r}_{\mathrm{ext}}} \cdot \int_{-\gamma_{\mathrm{k}}}^{+\gamma_{\mathrm{k}}} \mathrm{P}_{\text {saa }}\left(\theta-\theta_{\mathrm{R}}\right) \cdot \operatorname{Ea}(\theta) \cdot$ r.dr.d $\theta$

where:

$\mathrm{P}_{\text {saa }}\left(\theta_{\mathrm{R}}\right)=\mathrm{P}_{\text {saa } 0}+\sum_{\mathrm{h}=1}^{+\infty} \mathrm{P}_{\text {saah }} \cdot \cos \left[\mathrm{h} \cdot \mathrm{p} \cdot\left(\theta-\theta_{\mathrm{R}}\right)\right]$

and:

$\mathrm{E}_{\mathrm{a}}(\theta)=\mathrm{n}_{\mathrm{l}} \cdot \mathrm{n} \cdot \mathrm{I}_{\mathrm{a}} \cos (\mathrm{p} \theta)$

By introducing:

$A=n_{l}^{2} \cdot n \cdot I_{a} \cdot\left(r_{\text {ext }}^{2}-r_{\text {int }}^{2}\right)$

for all even h, the total flux linkage is given by:

$$
\begin{array}{|}
\Phi_{\mathrm{aa}}\left(\theta_{\mathrm{R}}\right)=\mathrm{A} \cdot \sum_{\mathrm{k}=1}^{\mathrm{n}}\left[2 \cdot \mathrm{P}_{\mathrm{aa} 0} \sin \left(\mathrm{p} \cdot \gamma_{\mathrm{k}}\right)\right]+\mathrm{A} \cdot \sum_{\mathrm{k}=1}^{\mathrm{n}} \sum_{\mathrm{h}=2}^{\infty} \mathrm{P}_{\mathrm{saah}} \cdot \\
\cos \left(\mathrm{h} \cdot \mathrm{p} \cdot \theta_{\mathrm{R}}\right)\left[\frac{\sin (\mathrm{h}+1) \mathrm{p} \cdot \gamma_{\mathrm{k}}}{\mathrm{h}+1}+\frac{\sin (\mathrm{h}-1) \mathrm{p} \cdot \gamma_{\mathrm{k}}}{\mathrm{h}-1}\right]
\end{array}
$$

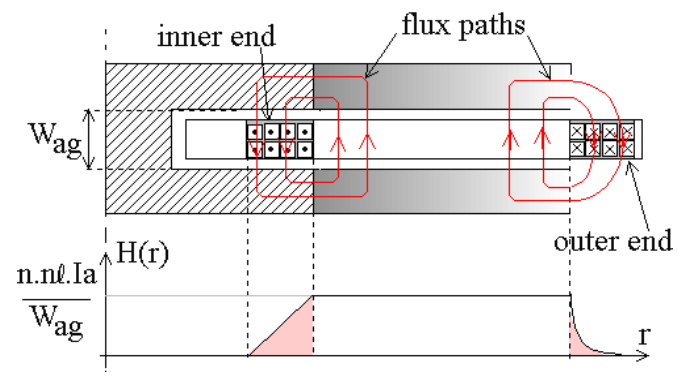

Fig. 14: Flux path and magnetic field in the ends of the armature winding

The expression in (15) has not taken the flux in the ends of the winding into account. For more accurate knowledge of the self-inductance, it is straightforward to calculate the flux of the inner ends of the windings (see Fig. 14). Since the airgap in this area is constant, a simple energy calculation using Ampere's law yields:
$\mathrm{W}_{\mathrm{aa} \sigma}=\int_{\mathrm{v}} \frac{\mu_{0}}{2} \mathrm{H}^{2} \cdot \mathrm{dv}=\frac{1}{2} \cdot \mathrm{L}_{\mathrm{aa} \sigma} \cdot \mathrm{I}_{\mathrm{a}}^{2}$

Then, considering the parameter values of the machine:

$\mathrm{L}_{\mathrm{aa \sigma}}=0.2 \mathrm{mH}$

which represents less than $10 \%$ of the total self-inductance (see Table 1). Lastly, assuming the flux of the outer ends of the windings to be negligible, the calculated flux is plotted in Fig. 15 (in accordance with Eq. 15 and by summing $\mathrm{L}_{\mathrm{aa \sigma}}$ ). Measurements have been conducted at low frequency; for different rotor positions, the measured impedance is identified with a series model that gives the self-inductance. The calculation and measurement at $5 \mathrm{~Hz}$ results in:

\begin{tabular}{lcc}
\cline { 2 - 3 } & $\mathrm{L}_{\mathrm{aa} \mathrm{m}}$ & $\mathrm{L}_{\mathrm{aad}}-\mathrm{L}_{\mathrm{aa} \mathrm{q}}$ \\
\hline Calculation & $2.83 \mathrm{mH}$ & $0.47 \mathrm{mH}$ \\
\hline Measurement & $2.85 \mathrm{mH}$ & $0.5 \mathrm{mH}$ \\
\hline Variation & $0.7 \%$ & $6 \%$ \\
\hline
\end{tabular}

Table 1: Self-inductance measurement and calculation values

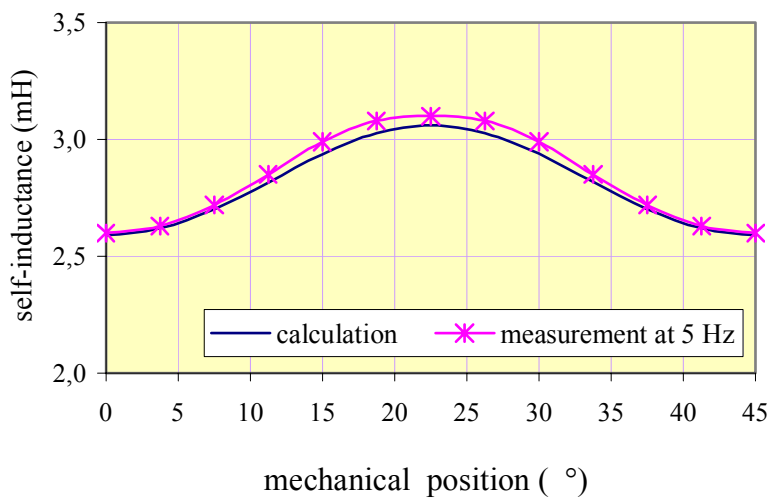

Fig. 15: Self-inductance of coil "a" (airgap = $10 \mathrm{~mm}$ )

Note that a low-frequency measurement is necessary; high frequency would create sizable losses in the solid steel discs, which are kept stationary, thereby changing the identified inductance.

\section{B. Armature mutual inductance}

Let's now consider the flux created by phase "a" in phase "b", which can be written as follows:

$\Phi_{\mathrm{ab} \_\mathrm{N}}\left(\theta_{\mathrm{R}}\right)=\sum_{\mathrm{k}=1}^{\mathrm{n}} \cdot \int_{\mathrm{R}_{\text {int }}}^{\mathrm{R}} \int_{\theta_{\mathrm{b}^{-}}}^{\theta_{\mathrm{b}^{+}}} \cdot \int_{\mathrm{sab}} \mathrm{P}_{\mathrm{ab}}\left(\theta-\theta_{\mathrm{R}}\right) \cdot \mathrm{E}_{\mathrm{a}}(\theta) \cdot$ r.dr.d $\theta$

where:

$\theta_{\mathrm{b}+}=\gamma_{\mathrm{k}}+2 \pi / 3 \mathrm{p}$

$\theta b-=-\gamma_{\mathrm{k}}+2 \pi / 3 \mathrm{p}$

By introducing:

$A=n_{l}^{2} \cdot n \cdot I_{a} \cdot\left(r_{\text {ext }}^{2}-r_{\text {int }}^{2}\right)$ 
we obtain (after a bit of algebraic manipulation):

$$
\begin{array}{|l}
\Phi_{\mathrm{ab}}\left(\theta_{\mathrm{R}}\right)=-\mathrm{A} \cdot \mathrm{P}_{\mathrm{sab} 0} \cdot \sum_{\mathrm{k}=1}^{\mathrm{n}} \sin \left(\mathrm{p} \cdot \gamma_{\mathrm{k}}\right) \\
\quad+\mathrm{A} \cdot \sum_{\mathrm{k}=1}^{\mathrm{n}} \cdot \sum_{\mathrm{h}=2}^{\infty} \mathrm{P}_{\mathrm{sabh}} \cdot \frac{\sin (\mathrm{h}+1) \mathrm{p} \cdot \gamma_{\mathrm{k}}}{\mathrm{h}+1} \cdot \cos \left(\mathrm{h} \cdot \mathrm{p} \cdot \theta_{\mathrm{R}}\right) \\
\quad-\mathrm{A} \cdot \sum_{\mathrm{k}=1}^{\mathrm{n}} \cdot \sum_{\mathrm{h}=2}^{\infty} \mathrm{P}_{\mathrm{sabh}} \cdot \frac{\sin (\mathrm{h}-1) \mathrm{p} \cdot \gamma_{\mathrm{k}}}{\mathrm{h}-1} \cdot \cos \left(\mathrm{h} \cdot \mathrm{p} \cdot \theta_{\mathrm{R}}+\frac{\pi}{3}\right)
\end{array}
$$

It should be pointed out that for an axial-field machine with sine-distributed f.m.m. (neglecting harmonics and asymmetric effects), the mutual inductance is half the selfinductance, like in the cylindrical machine [7]. Assuming this property remains valid for the flux in the inner ends, it is possible to deduce the mutual inductance relative to the inner ends of the winding from Laar. For a sine-distributed m.m.f., this inductance can then be expressed as follows:

$$
\mathrm{M}_{\mathrm{ab \sigma}}=-\frac{\mathrm{L}_{\mathrm{aa} \sigma}}{2}
$$

The measurement of mutual inductance Mab (see Fig. 16) is performed by virtue of measuring the e.m.f. induced in phase "a" when phase " $b$ " is fed by a sinusoidal current waveform at low frequency. The calculation (taking Maa into account) and measurement at $5 \mathrm{~Hz}$ result in:

\begin{tabular}{lcc}
\cline { 2 - 3 } & $\mathrm{M}_{\mathrm{ab} \mathrm{m}}$ & $\mathrm{M}_{\mathrm{abd}}-\mathrm{M}_{\mathrm{ab} \mathrm{q}}$ \\
\hline Calculation & $1.235 \mathrm{mH}$ & $0.45 \mathrm{mH}$ \\
\hline Measurement & $1.228 \mathrm{mH}$ & $0.52 \mathrm{mH}$ \\
\hline Variation & $0.6 \%$ & $12 \%$ \\
\hline
\end{tabular}

Table 2: Mutual inductance measurement and calculation values

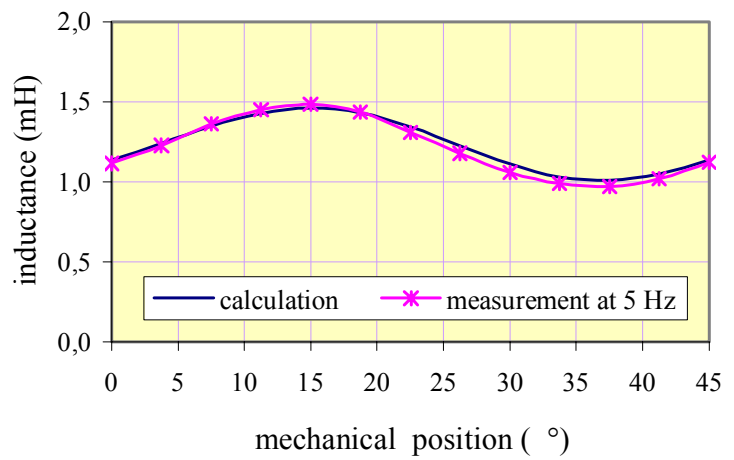

Fig. 16: Mutual inductance $\mathrm{M}_{\mathrm{ab}}$ distribution $($ airgap $=10 \mathrm{~mm})$

\section{Synchronous inductances}

Knowledge of the $\mathrm{d}$ - and q-axis synchronous inductances $\left(L_{d}\right.$ and $\left.L_{q}\right)$ is necessary to calculate reluctance torque. In initially assuming a symmetric model, it is then possible to express these inductances as follows:

$\mathrm{L}_{\mathrm{d}}=\mathrm{L}-\mathrm{M}+\frac{3}{2}\left(\mathrm{~L}_{\mathrm{d}}-\mathrm{L}_{\mathrm{q}}\right)$

$$
\mathrm{L}_{\mathrm{q}}=\mathrm{L}-\mathrm{M}-\frac{3}{2}\left(\mathrm{~L}_{\mathrm{d}}-\mathrm{L}_{\mathrm{q}}\right)
$$

where $\mathrm{L}$ is the mean self-inductance of one phase (such that $\left.\mathrm{L}_{\mathrm{aa}}=\mathrm{L}_{\mathrm{bb}}=\mathrm{L}_{\mathrm{cc}}=\mathrm{L}\right)$, $\mathrm{M}$ the mean mutual inductance between two phases (such that $\mathrm{M}_{\mathrm{ab}}=\mathrm{M}_{\mathrm{bc}}=\mathrm{M}_{\mathrm{ca}}=\mathrm{M}$ ), and $\mathrm{L}_{\mathrm{d}}$ and $\mathrm{L}_{\mathrm{q}}$ the d- and q-components of self-inductance, respectively. According to the previous measurements and calculations, the d- and q-axis synchronous inductances are equal to:

$\mathrm{L}_{\mathrm{d}}=4.8 \mathrm{mH}$

$\mathrm{L}_{\mathrm{q}}=\mathbf{3 . 3 \mathrm { mH }}$

\section{Asymmetric effects}

In reality, due to the discoid shape, asymmetric effects are present. Because flux density decreases from the top to the center of the airgap, the three mean self-inductances may, for example, be quite different (see Fig. 17). Hence:

$\mathrm{L}_{\mathrm{aa}} \neq \mathrm{L}_{\mathrm{bb}} \neq \mathrm{L}_{\mathrm{cc}}$

This phenomenon, including the position of the windings in the $2 \mathrm{D}$ semi-analytical model proposed in this paper, has been taken into account.

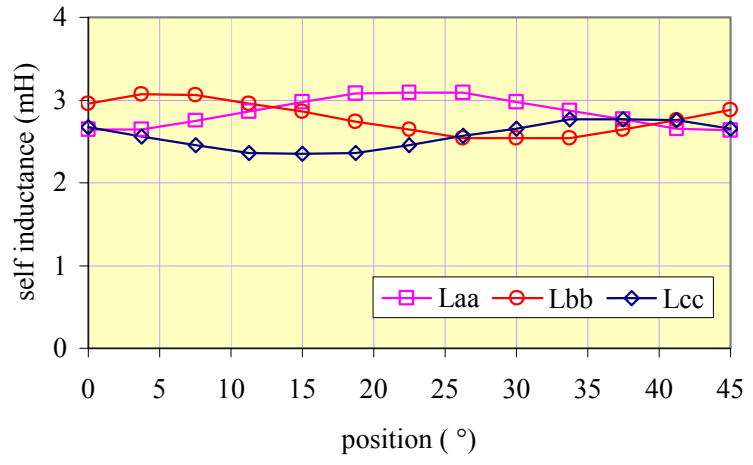

Fig. 17: Measurement of the 3 self-inductances

\section{TORQUE CALCULATION}

The torque expression, including both the synchronous torque $\mathrm{T}_{\mathrm{s}}$ and the reluctance torque $\mathrm{T}_{\mathrm{r}}$, can be written as follows:

$$
\mathrm{T}=\frac{3}{2} \mathrm{p} \cdot \mathrm{M}_{\mathrm{fa} M} \cdot \mathrm{I}_{\mathrm{f}} \cdot \mathrm{I}_{\mathrm{aM}} \cdot \cos \psi+\frac{3}{4} \mathrm{p}\left(\mathrm{L}_{\mathrm{d}}-\mathrm{L}_{\mathrm{q}}\right) \cdot \mathrm{I}_{\mathrm{aM}}^{2} \cdot \sin 2 \psi
$$

We then obtain:

$$
\mathrm{T}_{\mathrm{s} \max }=0.18 \mathrm{Nm}
$$

and:

$$
T_{\mathrm{r} \max }=18 \mathrm{mNm}
$$

A comparison between the hybrid torque $T_{s}$ and the reluctance torque $T_{r}$ shows that the reluctance effect is negligible in this machine when $\beta=45^{\circ}$ and $W_{a g}=10 \mathrm{~mm}$. 


\section{EDDY CURRENT LOSSES}

This section is intended to contribute to the estimation of eddy current losses in the active conductors due to the AC flux density component. The fact that the winding contains many thin conductors with a rectangular crosssection complicates the calculations. Moreover, it seems that no simple accurate solutions have yet to be proposed for correctly solving such a problem. An initial calculation derived from a 1D analysis for medium frequencies will also be presented herein to solve this typical problem.

\section{A. Losses in a single conductor}

Let's first consider a simple thin conductor with a rectangular cross-section (see Fig. 18). This conductor is not fed and has been placed in a magnetic field due to an external source. In assuming that the external flux distribution is not affected by the presence of eddy currents, the losses are calculated using the following equation, where $\mathrm{J}_{\mathrm{x}}$ is the $x$-component of eddy currents and $\mathrm{B}_{\mathrm{z}}$ the $z$-component of the flux density (not necessarily sine-distributed):

$\overrightarrow{\operatorname{rot}} \vec{J}_{\mathrm{x}}=-\sigma \cdot \frac{\partial \overrightarrow{\mathrm{B}_{\mathrm{z}}}}{\partial \mathrm{t}}$

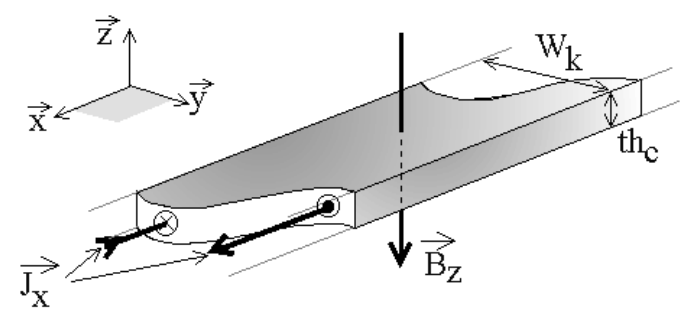

Fig.18: Single rectangular cross-section

In a Cartesian coordinate system for any field, the average power dissipated in the conductor is given by the following (with $\mathrm{L}$ being the length of the conductor):

$\mathrm{p}=\frac{\sigma \cdot \mathrm{L} \cdot \overline{\mathrm{W}_{\mathrm{k}}^{3}}}{12} \cdot\left(\frac{\partial \mathrm{B}_{\mathrm{z}}}{\partial \mathrm{t}}\right)_{\mathrm{RMS}}^{2}$

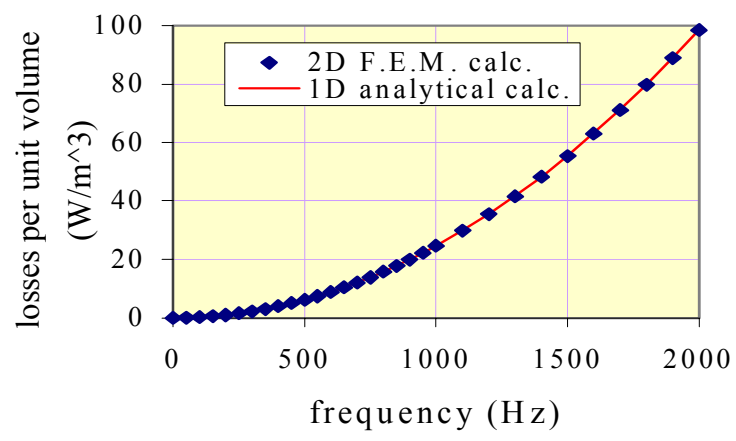

Fig. 19: Calculated losses vs. electrical frequency

Applied to a single conductor, Eq. 27 yields results similar to those of a 2D F.E.M. up until frequencies equal to $2 \mathrm{kHz}$, which corresponds to a velocity of $30,000 \mathrm{rpm}$ with a four-pole pairs machine. As regards the loss calculation, note that the RMS value of the $\left(\partial \mathrm{B}_{\mathrm{z}} / \partial \mathrm{t}\right)^{2}$ term is used instead of a Fourier series. Measurements and calculations have shown that this form provides the best results (see Fig. 21).

\section{B. Losses in the winding created by the field winding}

We will now calculate eddy current losses in the active conductors of the machine presented herein. Since the arc $\gamma_{k}$ (given by Eq. 1) of each conductor is small, the error incurred in assuming the uniform geometry presented in Fig. 18 remains low.

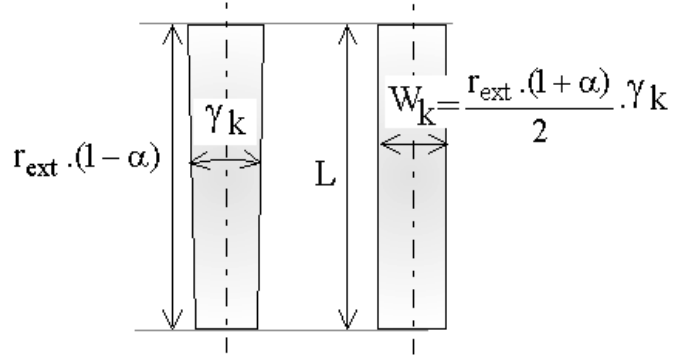

Fig. 20: Equivalent conductors

Let's now assume the proximity effects between conductors to be negligible:

$\mathrm{p}=\frac{\sigma \cdot \mathrm{p} \cdot \mathrm{n}_{\mathrm{I}} \cdot \mathrm{r}_{\mathrm{ext}} \cdot(1-\alpha)}{3} \cdot\left(\sum_{\mathrm{k}=1}^{\mathrm{n}} \gamma_{\mathrm{k}}^{3}\right) \cdot\left(\frac{\partial \mathrm{B}_{\mathrm{z}}}{\partial \mathrm{t}}\right)_{\mathrm{RMS}}^{2}$

The procedure employed to measure losses consisted of using a DC permanent magnet servomotor (AXEM - Alnico) mounted on the shaft of the synchronous machine. At a given speed, the current variation in the DC machine between the point where the field coil of the synchronous machine is fed and the point where it is not fed turns out to be directly proportional to the eddy current losses (via the armature constant). The measurements displayed in Fig. 21 serve to validate the model used for medium frequencies. In particular, it shows that calculation using the Fourier series until the eleventh harmonic leads to poor results. The peaks present in the flux induction distribution, especially for those layers close to the discs (see Fig. 8a), reflect high-frequency phenomena that actually get taken into account using the RMS value of the $\left(\partial \mathrm{B}_{\mathrm{z}} / \partial \mathrm{t}\right)^{2}$ term.

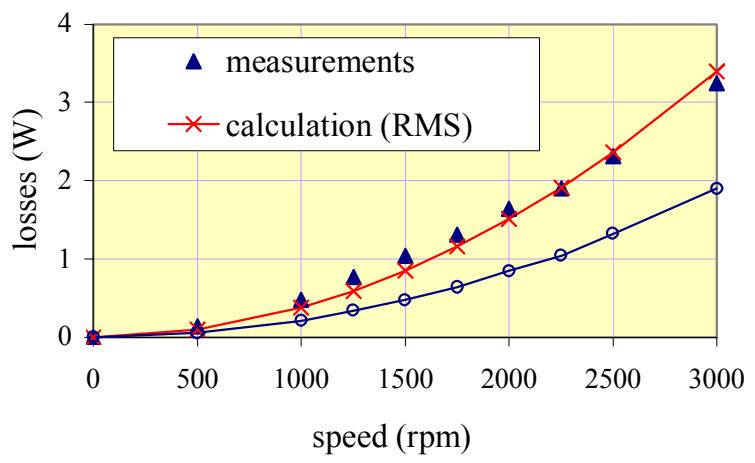

Fig. 21: Eddy current losses vs. Speed 


\section{Losses created by armature and field sources}

Let's now consider that the conductors are fed and placed in a magnetic field. This field, denoted $B_{R}$, is generated by the contribution of both the excitation field and the armature field. Two current density components therefore exist, which are possible to dissociate under linear conditions (see Fig. 22):

- one component due to the imposed armature source, and

- $\quad$ one component due to the eddy current created by $\mathrm{B}_{\mathrm{R}}$.
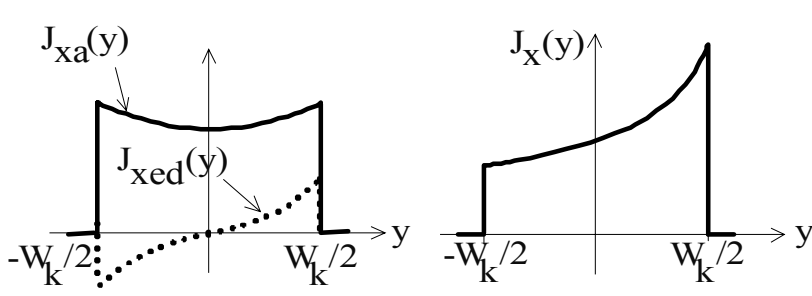

Fig. 22: Current density distribution and its two components

Under linear conditions, it is possible to sum the losses caused by these two sources [8]. The losses per unit volume can actually be expressed as follows:

$\frac{\mathrm{dp}}{\mathrm{dv}}=\frac{1}{2} \frac{\left(\mathrm{J}_{\mathrm{xa}}+\mathrm{J}_{\mathrm{xed}}\right)^{2}}{\sigma}$

and yield:

$\frac{\mathrm{dp}}{\mathrm{dv}}=\frac{1}{2 \sigma} . \mathrm{J}_{\mathrm{xa}}^{2}+\frac{1}{2 \sigma} . \mathrm{J}_{\mathrm{xed}}^{2}$

where the first term expresses the "classical" copper losses and the second the eddy current losses. In still assuming the external flux distribution not to be affected by the presence of eddy currents and considering only the eddy current losses in phase "a" (denoted $\mathrm{p}_{\mathrm{a}}$ ) in accordance with Eq. 28, the following is derived:

$\mathrm{p}_{\mathrm{a}}=\frac{\sigma \cdot \mathrm{p} \cdot \mathrm{n}_{\mathrm{I}} \cdot \mathrm{r}_{\mathrm{ext}} \cdot(1-\alpha)}{3} \cdot\left(\sum_{\mathrm{k}=1}^{\mathrm{n}} \gamma_{\mathrm{k}}^{3}\right) \cdot\left(\frac{\partial \mathrm{B}_{\mathrm{Ra}}}{\partial \mathrm{t}}\right)_{\mathrm{RMS}}^{2}$

with:

$B_{R a}=\left(P_{s a a} \cdot E_{a}\right)+\left(P_{s a b} \cdot E_{b}\right)+\left(P_{s a c} \cdot E_{c}\right)+\left(P_{s a f} \cdot E_{f}\right)$

Using the 2D semi-analytical model developed in Section $\mathrm{V}$, we have shown the possibility to express eddy current losses at any operating point, as long as flux density is not being affected by eddy currents. It should be noted that the losses given by Eq. 31 do not take PWM losses into account. These losses in turn create additional losses in both the conductors and the solid steel discs. For this reason, an experiment under operating conditions is difficult and still needs to be performed.

\section{CONCLUSION}

A new axial-field synchronous machine with armature and field winding fixed in the airgap, designed for a flywheel accumulator, has been presented and studied herein. Results obtained with a 2D semi-analytical model at the mean radius are satisfactory and have been validated by measurements. It is now possible to undertake design optimization (using, for example, a genetic algorithm).

\section{Parameter values:}

The main parameter values of the windings are as follows:

$\mathrm{n}=13$

$\mathrm{n}_{l}=4$

$\mathrm{n}_{\mathrm{f}}=96$

$\mathrm{W}_{\mathrm{i}}=0.2 \mathrm{~mm}$

$\mathrm{th}_{\mathrm{c}}=0.3 \mathrm{~mm}$

$\mathrm{th}_{\mathrm{i}}=0.2 \mathrm{~mm}$

number of armature coils/pole/element/phase number of layers/phase number of field coils insulation width between two conductors conductor thickness epoxy thickness

Other parameters:

$\mathrm{p}=4 \quad$ number of pole pairs

$\mathrm{r}_{\text {ext }}=0.1 \mathrm{~m}$ external radius of discs

$\mathrm{r}_{\text {int }}=0.05 \mathrm{~m}$ internal radius of discs

$\mathrm{r}_{\mathrm{s}}=0.02 \mathrm{~m}$

$\beta=45^{\circ}$

$\mathrm{W}_{\mathrm{ag}}=10 \mathrm{~mm}$ central core radius tooth arc

disc material airgap thickness

$\mathrm{th}_{\mathrm{d}}=10 \mathrm{~mm}$ C18 steel $\left(\mu_{\mathrm{r}}=1000\right)$

$\mathrm{I}_{\mathrm{aM}}=2 \mathrm{~A}$

$\mathrm{I}_{\mathrm{f}}=5 \mathrm{~A}$

disc thickness

maximum armature current

maximum field current

\section{References:}

[1] EUROPEAN COMMISSION, Community Research Report, "Energy storage - A key technology for decentralised power, power quality and clean transport", EUR 19978, Office for Official Publications of the European Communities, L-2985, Luxembourg.

[2] R. HEBNER, J. BENO and A. WALLS, "Flywheel Batteries come around again", IEEE Sprectrum, April 2002, pp. 46-51.

[3] H. BEN AHMED, B. MULTON, J. DELAMARRE, C. KERZREHO, J.Y. COGNARD and N. BERNARD, "Motor/generator with energised reluctance and coil in the air gap", PCT/FR 00/03459, 8 December 2001.

[4] A. LEAO RODRIGES, "Design of brushless coil-excited disc and drum type synchronous machine", ICEM'94, Vol. 3, pp. 36-39.

[5] N. BERNARD, H. BEN AHMED and B. MULTON, "Semianalytical inductance calculation on an axial-field synchronous machine for a flywheel storage system using surfacic permeances", IEEE-IEMDC'2001, Cambridge, Massachusetts, 17-20 June 2001, 9 pages.

[6] O. GERGAUD, H. BEN AHMED, B. MULTON and N. BERNARD, "Nouvelle architecture électromagnétique à réluctance variable excitée pour accumulateur électromécanique d'énergie", RIGE, Vol. 4, n 3-4, June 2001, pp. 367-390.

[7] A. HUGHES and T.J.E. MILLER, "Analysis of fields and inductances in air-cored and iron-cored synchronous machines", Proc. IEE, Vol. 124, n² 2, February 1977, pp. 121-126.

[8] M. SFAXI, M. GABSI, J.F. RIALLAND and F. BOUILLAUT, "Computation of additional losses at high frequencies of conductors in armature slots", ICEM'94, Vol. 3, pp. 693-697. 